\title{
Spontaneous intracranial extradural hematoma: Case report and literature review
}

\author{
Fan Xue Zheng, You Chao \\ Department of Neurosurgery, West China Hospital, Sichuan University, Chengdu Sichuan, 610041, P.R. China
}

\author{
Address for correspondence: \\ Dr. You Chao, \\ Department of Neurosurgery, \\ West China Hospital of Sichuan \\ University, 37 Guo Xue Xiang, \\ Wu Hou District, \\ Chengdu-610041 China. \\ E-mail:fxz109@sina.com
}

DOI: $10.4103 / 0028-3886.53288$

\begin{abstract}
Spontaneous extradural hematoma $(\mathrm{EDH})$ is an uncommon form of intracranial hematoma and is caused by the adjacent sinus and otic infections, dural vascular malformations and disorders of blood coagulation. We report spontaneous EDH in a 54-year old women with chronic kidney disease (CKD) on intermittent hemodialysis. She was successfully managed by conservative treatment. The $\mathrm{EDH}$ in her was probably related to the coagulation abnormalities associated with CKD, hemodialysis or heparin use during the dialysis.
\end{abstract}

Key words: Extradural, hematoma, intracranial, spontaneous

\section{Introduction}

Spontaneous extradural hematoma (EDH) is a very uncommon intracranial hematoma and is caused by adjacent infections, dural vascular malformations, tumors, disorders of blood coagulation. Till date there are 18 such documented cases in the literature. ${ }^{[1-16]}$ The first documentation of spontaneous EDH was by Schneider and Hegarty in 1951. ${ }^{[1]}$ We report spontaneous $\mathrm{EDH}$ in patient with chronic kidney disease (CKD) on intermittent hemodyalisis.

\section{Case Report}

A 54-year-old woman a known case of CKD (chronic glomerulonephritis) on intermittent haemodialysis between 2000 and 2007 was admitted for sudden onset headache associated with vomiting. Her medical history was otherwise unremarkable. There was no history any head trauma or trivial injury. On neurological examination she had mild clouding of consciousness and right side weakness (grade 3/5). Glasgow coma scale score was 12/15 (E3 V4 M5). Pupils were bilaterally reactive. Her vitals were normal. She was markedly anaemic, hemoglobin $7 \mathrm{~g} / \mathrm{dl}$. Coagulation profile was: Partial thromboplastin time 32.4 $\mathrm{s}$ (reference range 21.8-31.5 s), a prothrombin time of 1.20 (reference range 0.75-1.19), and platelet count 100,000/ $\mathrm{m}^{3}$ (reference range 130-400,000/ $\mathrm{mm}^{3}$ ). Blood urea nitrogen was $36 \mathrm{mg} / \mathrm{dl}$ (reference range $8-22 \mathrm{mg} / \mathrm{dl}$ ) and serum creatinine $8.3 \mathrm{mg} / \mathrm{dl}$ (reference range $0.5-1.3 \mathrm{mg} / \mathrm{dl}$ ). An urgent non-contrast CT scan showed left-sided temporoparietal EDH [Figures 1a and b].

A diagnosis of spontaneous EDH and CKD was made. The patient received a conservative management including mannitol and etamsylate. At the same time she also received transfusion of fresh frozen plasma $800 \mathrm{~mL}$, cryopreciptitate 5.0 units, fibrinogen 3.0 grams and lyophilized prothombin complex concentrate (LPCC) 1400 units. A repeat CT done after 20 days showed resolving hematoma [Figure 1c] Digital
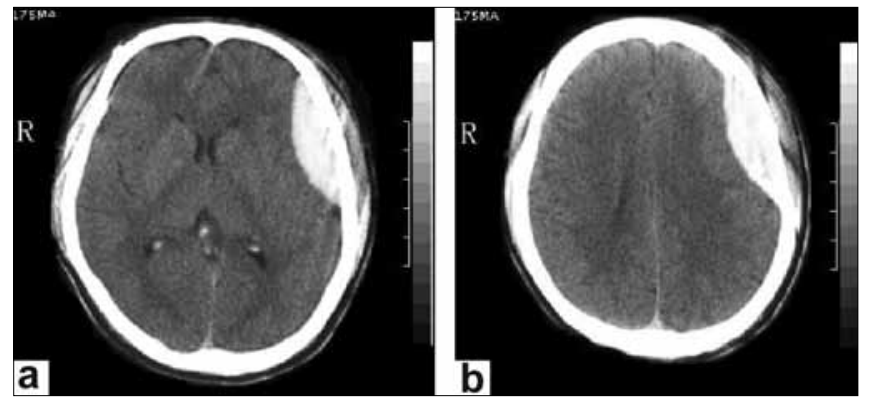

Figure 1: $(a, b)$ Non-contrast axial head CT revealing left temporo-parietal hyperdensity. No soft-tissue welling, fractures, or other radiographic signs of trauma are present (volume of hematoma is approximately $30 \mathrm{ml}$ ) 
subtraction angiography (DSA) done after 25 days of the ictus to ascertain the reasons of hematoma was normal. [Figures 1e and f].

A month later, she was asymptomatic and CT scan demonstrated complete resolution of haematoma [Figure 1d]. During a 6-month follow-up, she remained well with no neurological deficit and she was being treated for CKD with intermittent haemodialysis.

\section{Discussion}

Spontaneous EDH is an uncommon neurological emergency and requires urgent investigation and treatment. Till date including our case only 19 cases [Table 1] were documented in the literature. ${ }^{[1-16]}$ Of the 18 patients documented in the literature, adjacent cranio-facial infections were the causes in 14 patients: Paranasal infection in nine $(3,5,8-13)$, chronic otitis in four $(1,2,4,6)$, and furuncle on the ala nasi in one (1). The proposed mechanism was intracranial spread of

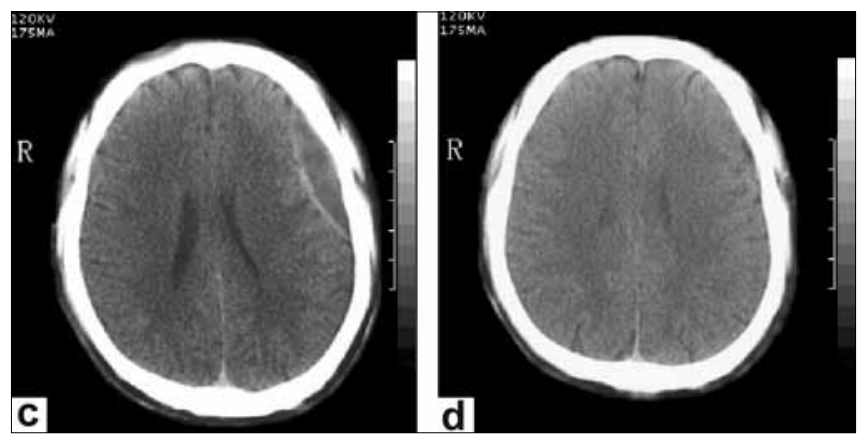

Figure 1: (c, d) Non-contrast head CT obtained after 20 days, revealing hematoma begin liquefaction and resolution and minimal decrease. Head CT after one month, revealing complete absorption of hematoma the infection from the craniofacial site and the vasculitis associated with the infection, bleeding from the rupture of vasculitic vessel and subsequent expansion..$^{[8-11]}$ In all these, except the patients who died, hematoma was evacuated by surgery and the patients were subsequently exposed to antibiotics. In one of the patients the EDH was due to rupture of the aneurysm of middle meningeal artery proven by pre-operative cerebral angiogram. The hematoma was surgically evaculated ${ }^{[6]}$ In the patient reported by Wani et al., ${ }^{[16]}$ there was erosion of the vessels by the intradiploic epidermoid tumor.

Intracranial hemorrhages, intracerebral, ${ }^{[17]}$ subdural, ${ }^{[18]}$ and $\mathrm{EDH}^{[14,16]}$ have been documented in patients with $\mathrm{CKD}$ and uremia. However the exact mechanism for this complication is uncertain, the possible mechanisms may be more than one. In our patient underlying vascular malformation was excluded by cerebral angiogram Probably the coagulation abnormalities associated with uremia, heparin use during the hemodialysis or hemodialyis per se may be the factors for the EDH. In her

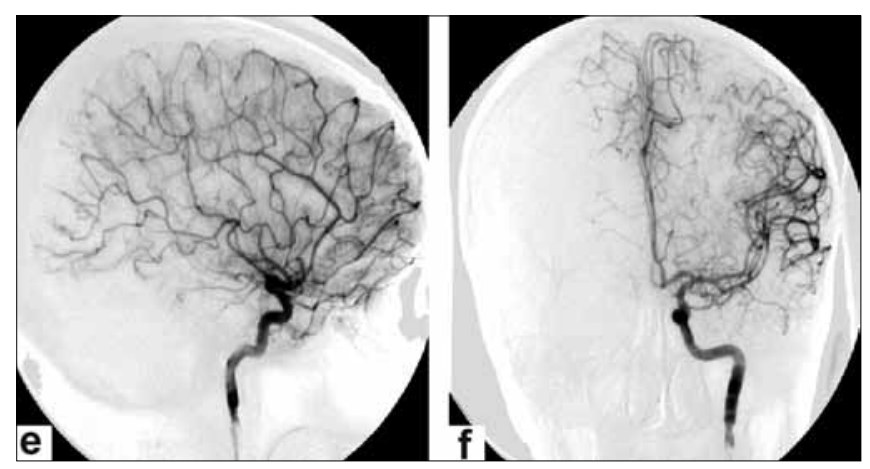

Figure 1: (e, f) An orthophoric and lateral view of left carotid angiography obtained 25 days after being admitted to hospital revealing nomal extraand intracranial vascular anatomy

\begin{tabular}{|c|c|c|c|c|}
\hline Author & Age/sex & Probably cause & Hematoma site & Surgery \\
\hline Kelly et al. ${ }^{[3]}$ & $11 / M$ & Pansinusitis & Frontal & Yes \\
\hline Raiput et al. ${ }^{[5]}$ & $18 / M$ & Maxillary sinusitis & Frontal & Yes \\
\hline Marks et al. ${ }^{[7]}$ & $31 / M$ & Pansinusitis & Frontal & Yes \\
\hline \multirow[t]{2}{*}{ Sanchis et al. ${ }^{[6]}$} & $13 / \mathrm{M}$ & Otitis media & Right temporal & Yes \\
\hline & $59 / F$ & $\begin{array}{l}\text { Aneurysm of the middle menin- } \\
\text { geal artery }\end{array}$ & Right temporal & Yes \\
\hline Papadopoulos et al. ${ }^{[10]}$ & $17 / M$ & Right frontal sinusitis & Right frontal & Yes \\
\hline Ataya $^{[8]}$ & $31 / F$ & Pansinusitis & Frontal & Yes \\
\hline Sakamoto et al ${ }^{[9]}$ & $16 / M$ & Maxillary sinusitis & Frontal & Yes \\
\hline Griffiths et al. ${ }^{[11]}$ & $16 / M$ & Cleft palate with frontal sinusitis & Frontal & Yes \\
\hline Moonis et al..$^{[12]}$ & $21 / M$ & Sphenoiditis & Temporal & Yes \\
\hline Saisawat et al. ${ }^{[13]}$ & $14 / F$ & Pansinusitis & Frontal & Yes \\
\hline Kiarash et al. ${ }^{[14]}$ & $16 / \mathrm{M}$ & Uremai & Frontotemporo-parietal & Yes \\
\hline \multirow[t]{2}{*}{ Schneider et al. ${ }^{[1]}$} & $21 / M$ & Otitis media* & Middle fossa & No \\
\hline & $21 / M$ & Furuncle of ala nasi & Anterior fossa & Yes \\
\hline Novaes et al. ${ }^{[2]}$ & $26 / M$ & Otitis media & Temporal & Yes \\
\hline Clein $\mathrm{LJ}^{[4]}$ & $18 / \mathrm{M}$ & Otitis media ${ }^{[8]}$ & Fronto-parietal & No \\
\hline Wani $A A^{[15]}$ & $60 / M$ & Intradiploic epidermoid tumor & Calvarium & Yes \\
\hline Shimokawa $S^{[16]}$ & $54 / \mathrm{M}$ & Uraemia & Right frontoparietotemporal & Yes \\
\hline Our case & $54 / F$ & CKD, uremia & Right temporal & No \\
\hline
\end{tabular}

*These two patients died and hematoma was confirmed at autopsy 
both the partial thromboplastin time and prothrombin time were in the upper limit of normal and platelet count was on the lower limit of the normal. However we have not done the platelet function tests. Platelet dysfunction has been documented in patients with uremia. ${ }^{[19]}$ In uremia nitric oxide may inhibit platelet activation, adhesion and aggregation by activating the platelet guanylate cyclase. ${ }^{[20]}$ During hemodialysis there can be changes in the serum and cerebrospinal fluid osmolality which can result in intracranial pressure fluctuations. ${ }^{[21]}$ It is possible that such changes may cause vascular damage and bleeding. In uremic patients with spontaneous EDH surgery can be avoided as the mechanism of bleeding is multifactorial and the coagulation abnormality should be corrected. However surgery may be indicated if the patient has midline shifts, elevated intracranial pressure, and progressive clinical deterioration. We managed our patient conservatively as she had no evidence of midline shifts.

\section{References}

1. Schneider RC, Hegarty WM. Extradural hemorrhage as a complication of otological and rhinological infections. Ann Otol Rhinol Laryngol 1951;60:197-206.

2. Novaes V, Gorbitz C. Extradural hematoma complicating middle ear infection: Report of a case. J Neurosurg 1965;23:352-3.

3. Kelly DL Jr, Smith JM. Epidural hematoma secondary to frontal sinusitis: Case report. J Neurosurg 1968;28:67-9.

4. Clein LJ. Extradural haematoma associated with middle ear infection. Can Med Assoc J 1970;102:1183-4.

5. Rajput AJ, Rozdilsky B. Extradural hematoma following frontal sinusitis: Report of a case and review of the literature. Arch Otolaryngol 1971;94:83-6.

6. Sanchis JF, Orozco M, Cabanes J. Spontaneous extradural haematomas. J Neurol Neurosurg Psychiatry 1975;38:577-80.

7. Marks SM, Shaw MD. Spontaneous intracranial extradural hematoma.
J Neurosurg 1982;57:708-9.

8. Ataya NL. Extradural haematoma secondary to chronic sinusitis: A case report. J Laryngol Otol 1986;100:951-3.

9. Sakamoto T, Harimoto K, Inoue S, Konishi A. Extradural hematoma following maxillary sinusitis: Case illustration. J Neurosurg 1997;87:132.

10. Papadopoulos MC, Dyer A, Hardwidge C. Spontaneous extradural haematoma with sinusitis. J R Soc Med 2001;94:588-9.

11. Griffiths SJ, Jatavallabhula NS, Mitchell RD, Spontaneous extradural haematoma associated with craniofacial infections: Case report and review of the literature. Br J Neurosurg 2002;16:188-91.

12. Moonis G, Granados A, Simon SL. Epidural hematoma as a complication of sphenoid sinusitis and epidural abscess: A case report and literature review. Clin Imaging 2002;26:382-5.

13. Chaiyasate S, Halewyck S, Van Rompaey K, Clement P. Spontaneous extradural hematoma as a presentation of sinusitis: Case report and literature review. Int J Pediatr Otorhinolaryngol 2007;71:827-30.

14. Shahlaie K, Fox A, Butani L, Boggan JE. Spontaneous epidural hemorrhage in chronic renal failure : A case report and review. Pediatr Nephrol 2004;19:1168-72.

15. Wani AA, Ramzan AU, Kirmani AR, Bhatt AR, Hamdani N, Zargar J. Intradiploic epidermoid causing spontaneous extradural hematoma: Case report. Neurosurgery 2008;62:971.

16. Shimokawa S, Hayashi T, Anegawa S, Nakashima S, Tsutsumi K, Nakagawa S, et al. Spontaneous epidural hematoma in a patient undergoing hemodialysis: A case report. No To Shinkei 2003;55:163-6.

17. Aguilar MI, Hart RG, Kase CS, Freeman WD, Hoeben BJ, García RC, et al. Treatment of warfarin-associated intracerebral hemorrhage: Literature review and expert opinion. Mayo Clin Proc 2007;82:82-92.

18. Leonard A, Shapiro FL. Subdural hematoma in regularly hemodialyzed patients. Ann Intern Med 1975;82:650-8.

19. Sung J, Hsieh CC, Yu CY, Huang JJ. Acute spontaneous spinal epidural hematoma in a hemodialysis patient with a bleeding tendency. Nephron 2002;91:358-60.

20. Boccardo P, Remuzzi G, Galbusera M. Platelet dysfunction in renal failure. Semin Thromb Hemost 2004;30:579-89.

21. Kurokawa Y, Suzuki S, Hashi K, Uede T, Matsumura S, Kawahara T, et al. Elevation of intracranial pressure during hemodialysis-continuous measurement of cerebrospinal fluid pressure in a patient with acoustic neurinoma. No To Shinkei 1990;42:569-73.

Accepted on 24-01-2009

Source of Support: Nil, Conflict of Interest: None declared. 